\title{
Rancang Bangun Robot Penari Humanoid dengan 25 DoF untuk Melakukan Gerakan Tari Remo
}

\author{
Muchammad Ainur Fahd, Djoko Purwanto, dan Muhammad Hilman Fatoni \\ Departemen Teknik Elektro, Fakultas Teknologi Elektro, Institut Teknologi Sepuluh Nopember (ITS) \\ e-mail: hilmanfatoni@bme.its.ac.id
}

\begin{abstract}
Abstrak-Seiring dengan perkembangan zaman, teknologi saat ini berkembang secara pesat. Sebut saja salah satu teknologi tersebut adalah dibidang robot. Saat ini robot mulai banyak diaplikasikan, contohnya seperti untuk mempermudah pekerjaan manusia, hiburan, militer dan masih banyak lagi. Salah satu jenis robot yang banyak dikembangkan saat ini adalah robot humanoid. Robot humanoid merupakan robot yang hampir menyerupai manusia secara umum dan memiliki pergerakan layaknya manusia pada umumnya seperti berjalan, berdiri dan lain sebagainya. Saat ini banyak negara di dunia yang berlomba-lomba untuk menciptakan robot humanoid yang memiliki kecerdasan buatan layaknya manusia. Salah satunya robot Atlas yang dibuat oleh Boston Dynamics yang bisa melakukan gerakan salto. Di Indonesia sendiri, perkembangan robot humanoid kebanyakan masih dalam ukuran kecil (kids size) dan digunakan untuk perlombaan seperti robot sepak bola dan robot seni tari. Pengembangan robot seni tari sendiri saat ini masih sebatas penyempurnaan gerak, keseimbangan dan komunikasi antar robot. Desain mekanik pada robot terdahulu juga dirasa tidak memenuhi Center of Gravity maupun Center of Mass.[1]. Oleh karena itu perlu dibuat sebuah platform robot tari humanoid yang baru agar lebih luwes untuk melakukan gerakan tarian remo. Dari hasil pengujian, robot humanoid yang dinamai virose ini bisa dikatakan lebih kokoh dari segi kontruksi sehingga lebih stabil untuk berjalan. Selain itu pergerakan tangan lebih luwes dengan beberapa penambahan frame gerakan. Secara keseluruhan robot dapat melakukan gerakan tari remo yang disesuaikan dengan tarian aslinya.
\end{abstract}

Kata Kunci-Robot Humanoid, Robot Penari, Kontes Robot Seni Tari Indonesia.

\section{PENDAHULUAN}

$\mathrm{T}$ EKNOLOGI di bidang robotika semakin hari semakin berkembang, hal ini mempengaruhi akan kebutuhan robotika semakin meningkat, seperti bidang industri, sipil, medis, olahraga, manajemen bencana, sampai di bidang kesenian. Riset pada bidang robotika pun terbilang semakin banyak, tentunya hal ini bukan tanpa tujuan. Demikian juga penelitian tentang robot humanoid atau robot yang menyerupai manusia. Robot humanoid ini bisa melakukan banyak tugas ataupun tujuan seperti olahraga, manajemen bencana, dan kesenian.

Di Indonesia sendiri penelitian atau pengembang tentang robot humanoid semakin pesat. Hal ini dikarenakan adanya perlombaan baik itu tingkat Regional, Nasional, bahkan Internasional. Kontes Robot Indonesia (KRI) adalah suatu kegiatan perlombaan yang diselenggarakan oleh Kementerian Riset, Teknologi, dan Pendidikan Tinggi Republik Indonesia (Kemenristek dikti). Pada KRI terdapat berbagai divisi, salah satunya adalah Kontes Robot Seni Tari Indonesia (KRSTI). Divisi ini merupakan suatu ajang kompetisi perancangan, pembuatan, dan pemrograman robot yang disertai dengan unsur-unsur seni dan budaya bangsa Indonesia khususnya seni tari yang telah terkenal di bumi pertiwi. Untuk KRSTI 2018, kembali guna membangkitkan kecintaan dan pelestarian budaya-budaya Nasional maka tema yang diangkat adalah Robot Penari Remo. [2].

Pada pertandingan Kontes Robot Seni Tari Indonesia, robot diharuskan dapat melakukan beberapa gerakan tarian ketika ada alunan musik dan berhenti ketika tidak ada alunan musik. Musik diperdengarkan melalui Audio Bluetooth Transmitter dari juri dan didengarkan oleh robot dengan Audio Bluetooth Receiver. Selain itu, robot harus melakukan tarian mulai dari zona Start - zona A - zona B zona $\mathrm{C}$ - zona Finish. Dimana tiap zona harus dilewati untuk mendapatkan point nilai dan bonus.

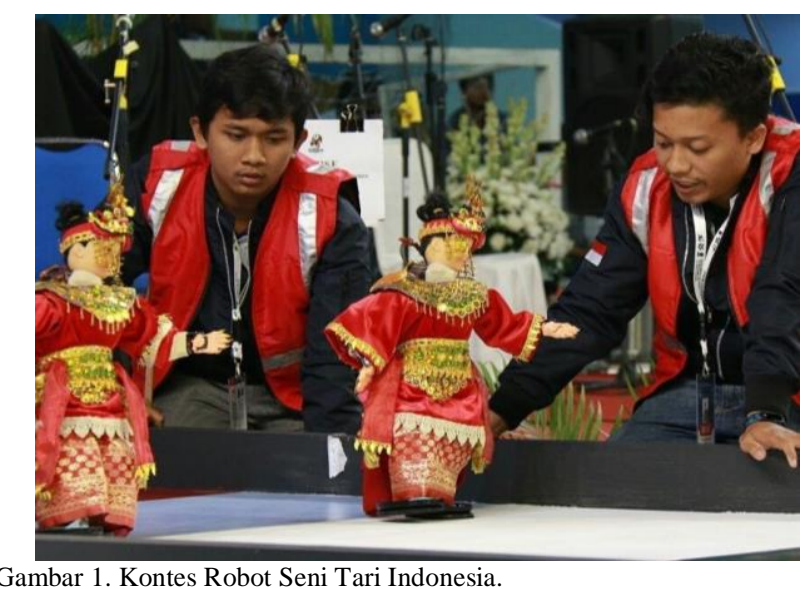

Dalam rangka pengembangan Robot Seni Tari humanoid, penelitian ini dilakukan dengan menggunakan 25 DoF (Degree of Freedom) yang diharapkan dapat melakukan gerakan tari remo. Pengembangan Robot Seni Tari sendiri saat ini masih sebatas penyempurnaan gerak keseimbangan dan komunikasi antar robot. Desain mekanik terdahulu dirasa tidak mumpuni untuk melakukan gerakan tari remo dan dengan rule saat ini. Dimana robot harus melakukan beberapa variasi gerakan dengan panjang lintasan tiga meter dengan durasi musik hanya 2 menit 54 detik. Oleh karena itu perlu dibuat platform robot tari humanoid yang baru agar dapat melakukan gerakan melangkah lebih jauh dan lebih cepat. Selain itu gerakan tangan juga tidak kalah penting, tangan diharapkan dapat melakukan gerakan yang lebih luwes ketika melakukan gerak tarian remo.

\section{DASAR TEORI}

\section{A. Kontes Robot Seni Tari Indonesia (KRSTI)}

Kontes Robot Indonesia (KRI) adalah suatu kegiatan perlombaan yang diselenggarakan oleh Kementerian Riset, Teknologi, dan Pendidikan Tinggi Republik Indonesia (Kemenristek dikti). Pada KRI terdapat berbagai divisi, salah satunya adalah Kontes Robot Seni Tari Indonesia (KRSTI). Divisi ini merupakan suatu ajang kompetisi 
perancangan, pembuatan, dan pemrograman robot yang disertai dengan unsur-unsur seni dan budaya bangsa Indonesia khususnya seni tari yang telah terkenal di bumi pertiwi. Untuk KRSTI 2018, kembali guna membangkitkan kecintaan dan pelestarian budaya-budaya Nasional maka tema yang diangkat adalah Robot Penari Remo.

Pada pertandingan Kontes Robot Seni Tari Indonesia, robot diharuskan dapat melakukan beberapa gerakan tarian ketika ada alunan musik dan berhenti ketika tidak ada alunan musik. Musik diperdengarkan melalui Audio Bluetooth Transmitter dari juri dan didengarkan oleh robot dengan Audio Bluetooth Receiver. Selain itu, robot harus melakukan tarian mulai dari zona Start - zona A - zona B zona $\mathrm{C}$ - zona Finish. Dimana tiap zona harus dilewati untuk mendapatkan point nilai dan bonus.

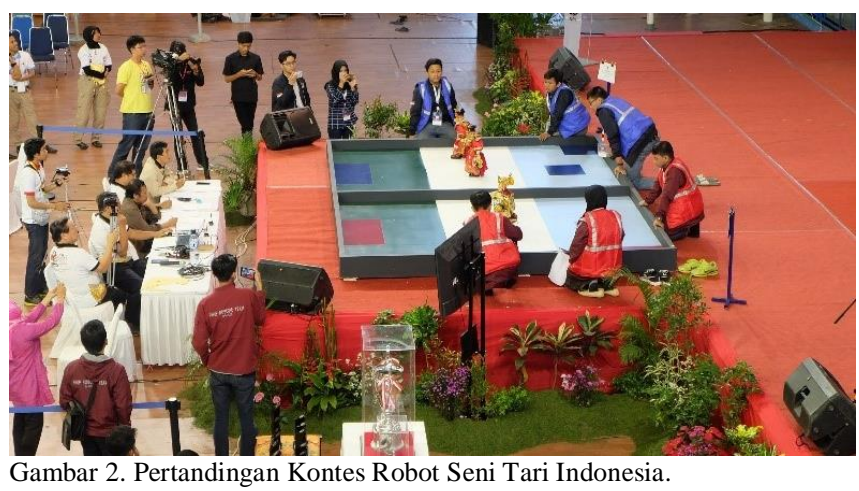

\section{B. Kinematika Robot}

Kinematika adalah analisa tentang gerak yang mengacu pada referensi koordinat tanpa memperhatikan faktor-faktor gaya yang menyebabkan pergerakan tersebut. Model kinematika mempresentasikan hubungan antara end effector dalam ruang tiga dimensi. Dalam kinematika robot, terdapat dua macam yaitu forward kinematics dan inverse kinematics.

Pada Forward Kinematic data yang menjadi inputan adalah sudut pada masing-masing joint sedangkan data outputan berupa posisi koordinat. Sehingga posisi masingmasing joint dan model struktur mekanik robot. Sedangkan Inverse Kinematics, data yang menjadi inputan meruapakan posisi koordinat kartesian dan data outputnya berupa sudut pada masing-masiing joint. Sehingga Inverse Kinematics dan Forward Kinematics saling berkebalikan.

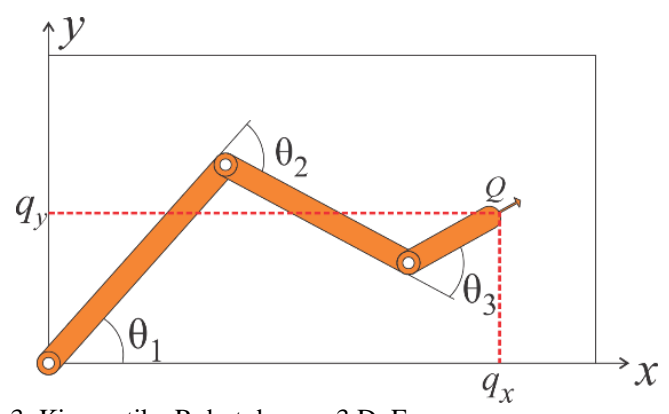

Gambar 3. Kinematika Robot dengan 3 DoF.

\section{Platform Robot Humanoid Darwin-OP [3]}

Darwin-OP merupakan kepanjangan dari Dynamic Anthropomorphic Robot with Intelligence Open Platform, merupakan robot yang diproduksi oleh Robotis atas kerjasama dengan University Pennsylvania. Robot ini sengaja dikembangkan untuk keperluan riset dalam permainan speak bola humanoid. Robot Darwin-OP memilik perangkat keras yang terdiri dari sebuah PC yang bernama Fit-PC2i, kamera Logitech C905, motor servo MX-28T dan sub controller CM-730. PC pada robot sendiri menggunakan Operation System berbasis Linux. PC dapat disambungkan melalui jaringan nirkabel Wi-Fi. Modul sub controller CM730 merupakan mikrokontroller berbasis ARM yang digunakan untuk mengontrol seluruh servo MX-28T pada robot Darwin. CM-730 memiliki gyroscope dan accelerometer yang berfungsi untuk menstabilkan gerakan robot dan mendeteksi robot jatuh. Darwin OP ini merupakan open platform, dimana seluruh informasi terkait sistem, mekanik, dan sebagainya sudah di publikasikan. Jadi dimungkinkan untuk membuat sebuah robot Darwin OP yang lebih.

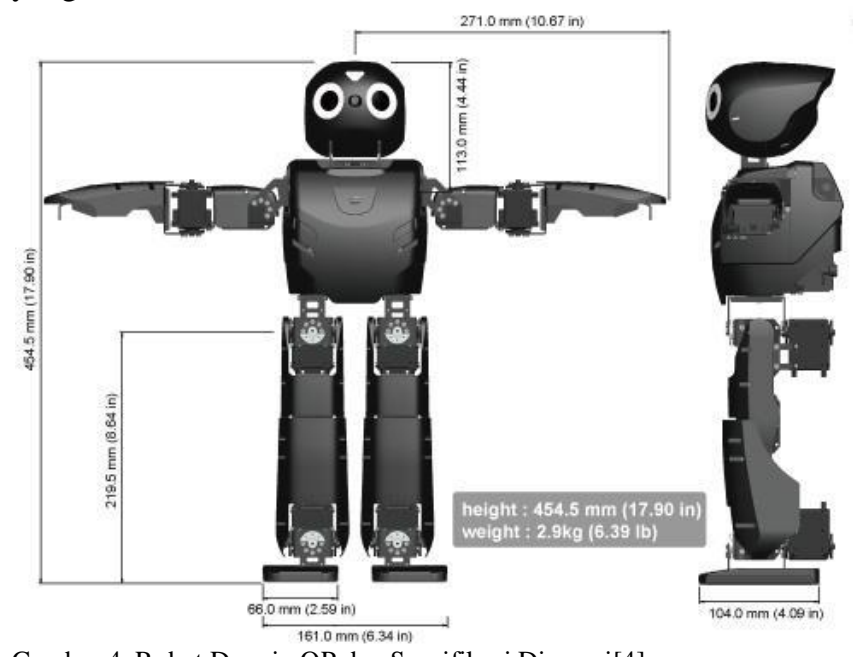

Gambar 4. Robot Darwin OP dan Spesifikasi Dimensi[4].

\section{Servo Controller CM-730}

CM-730 merupakan sub controller yang digunakan oleh robot Darwin OP yang mempunyai fungsi sebagai pengontrol seluruh servo MX-28T. CM-730 ini pada dasarnya berbasis ARM Cortex 32-bit CPU (clocked @72MHz). Untuk mengakses CM-730 perlu sebuah program yang ditempatkan pada Fit-PC2i. Berikut adalah beberapa fitur dari Sub controller CM-730. CM-730 ini memiliki 10 Bit ADC dengan range 0 - 1023, untuk port ADC perlu dimodifikasi dengan penambahan female header. Tabel 1 merupakan spesifikasi dari CM-730.

Tabel 1.

spesifikasi dari CM-730

\begin{tabular}{ll}
\hline \hline \multicolumn{1}{c}{ Fitur } & \multicolumn{1}{c}{ Spesifikasi } \\
\hline & STMicroelectronics 32F103RE \\
CPU & ARM Cortex 32-bit CPU (clocked \\
& @ 72 MHz) (512KB Flash, 64KB \\
& SRAM) \\
& 5x LED, 2x RGB, 3x Button, 1x \\
Interface & Buzzer \\
& $13 x$ ADC / I/O Ports \\
External ports & 3 -axis gyroscope, 3-axis \\
& accelerometer, supply voltage \\
Sensor & sensor \\
& USB Port, Serial Port, 5x TTL \\
Communication & Ports (for dynamixel) \\
& Audio amp gain: 20, mic amp gan \\
Audio \& Mic Amp & 2027 \\
& Dynamixel Power Control Unit, \\
Additional & Head board port, Interface board \\
& port \\
Supply Voltage & $8 \mathrm{~V}-16.8 \mathrm{~V}$ \\
Current Consumption & $150 \mathrm{~mA}$ \\
Dimension & $80.0 \mathrm{~mm} \times$ \\
Operation temperature & $-65^{\circ} \mathrm{C}$ to $+80^{\circ} \mathrm{C}$ \\
Weight & $51 \mathrm{~g}$ \\
\hline \hline
\end{tabular}




\section{E. Platform Robot Humanoid Kondo KHR-3HV}

Robot humanoid Kondo KHR-3HV merupakan robot humanoid yang diproduksi oleh perusahaan Kondo Kagaku co, perusahaan ini berasal dari Jepang. Robot humanoid ini memiliki desain awal sebanyak 17 buah Degree of Freedom (DoF) berupa servo serial. Kemudian desain robot ini dikembangkan agar mampu melakukan gerakan yang lebih beragam menjadi 25 sendi gerak dengan berupa 21 servo serial dan 4 buah servo analog dengan kendali menggunakan Pulse Modulation Width (PWM).

Secara umum di jepang, robot humanoid jenis KHR3HV digunakan untuk robot battle (Robot Petarung) dengan kendali secara manual menggunakan remote control.

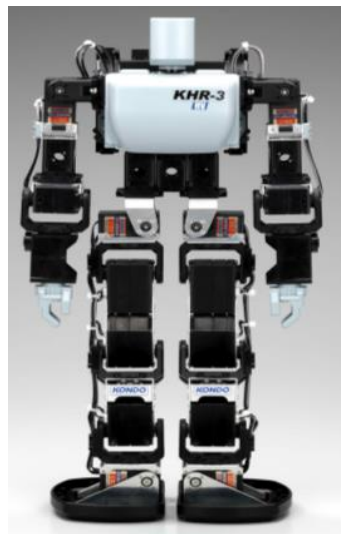

Gambar 5. Platform Robot Kondo KHR-3HV [5].

\section{F. Servo Controller RCB-4HV}

RCB-4HV merupakan sebuah kontroller untuk menggerakkan servo jenis KRS-2552HV. Untuk servo KRS$2552 \mathrm{HV}$ sistem pengaturannya menggunakan sistem komunikasi serial. Kontroller yang digunakan untuk mengatur gerakan servonya adalah RCB-4HV. Controller ini memiliki 2 output serial servo dan memiliki 10 input analog serta GPIO sebanyak 10 juga.

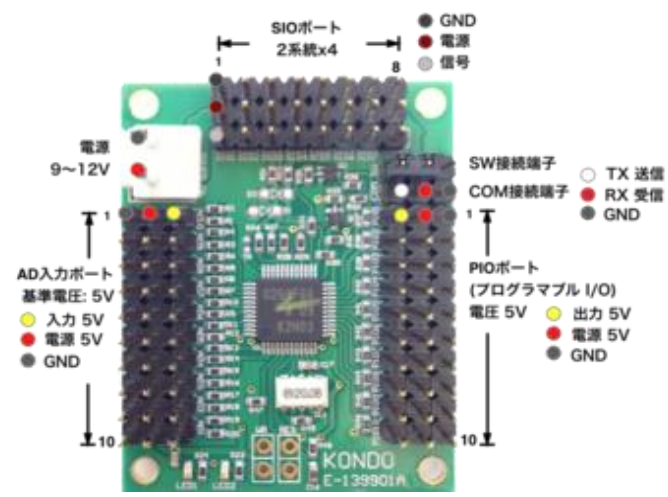

Gambar 6. Servo Controller RCB-4HV [5].

\section{PERANCANGAN SISTEM}

Dalam bab ini akan dijelaskan tentang desain robot, perancangan sistem dan implementasi secara keseluruhan, mulai dari desain mekanik robot, desain sistem elektronik, desain komunikasi pada robot, perancangan gerakan tari remo, implementasi desain mekanik robot, implementasi sistem elektronik, dan implementasi komunikasi pada robot. Perangkat keras yang digunakan adalah dua buah robot humanoid Virose Master dan Virose Slave yang dirancang dengan 25 derajat kebebasan dengan menggunakan beberapa kontroller seperti Fit-PC2i sebagai komputer utama dengan sistem operasi Linux dan mikrokontroller CM-730 sebagai kontroller aktuator servo dynamixel MX$28 \mathrm{~T}$ serta mikrokontroller Kondo RCB-4HV sebagai kontroller aktuator servo Kondo. Karena pada dasarnya robot humanoid ini didesain menggunakan 2 platform yang berbeda. Ditambah lagi mikrokontroller Arduino Nano sebagai pengolah data dari sensor suara. Dalam sistem ini, komputer utama mengolah data motion dan mengirimkannya ke mikrokontroller CM-730 untuk mengirimkan perintah sudut ke servo dynamixel MX-28T. Sedangkan mikrokontroller Kondo RCB-4HV mengolah data motion dan mengirimkan langsung ke servo Kondo. Pada perancangan robot humanoid ini mengacu pada rule Kontes Robot Seni Tari Indonesia 2018.

\section{A. Desain Mekanik Robot}

Desain mekanik robot humanoid ini bertujuan untuk mengikuti pertandingan Kontes Robot Seni Tari Indonesia 2018 dengan mengikuti beberapa ketentuan dari para dewan juri. Pada dasarnya robot humanoid yang akan dirancang menggunakan dua platform yang berbeda yaitu dengan platform Darwin OP dari Robotis dan KHR-3HV dari Kondo Robot. Platform Darwin OP digunakan karena kelebihannya pada kekuatan dan kecepatan servo yang digunakan, sehingga cocok untuk dijadikan tumpuan kaki dan daerah dada. Sedangkan platform Kondo digunakan karena kelebihannya pada sisi berat yang ringan dan dimensi yang tidak terlalu besar dibandingkan servo dari Darwin OP.

Untuk desain mekanik ini sendiri merujuk pada buku panduan Kontes Robot Seni Tari Indonesia yang meliputi beberapa ketentuan seperti tinggi maksimum robot, berat maksimum robot, jumlah DoF minimal,lebar rentang tangan kanan sampai kiri dan lain-lain. Untuk lebih jelasnya dapat dilihat Tabel 2.

Tabel 2.

Ketentuan Dimensi Robot

\begin{tabular}{llcc}
\hline \hline \multirow{2}{*}{ No } & \multicolumn{1}{c}{ Deskripsi } & $\begin{array}{c}\text { Ukuran } \\
\text { Maksimal }\end{array}$ & $\begin{array}{c}\text { Ukuran } \\
\text { Robot }\end{array}$ \\
\cline { 3 - 4 } & & $55 \pm 5 \mathrm{~cm}$ & $54 \mathrm{~cm}$ \\
2 & Tinggi robot & $60 \mathrm{~cm}$ & $54 \mathrm{~cm}$ \\
3 & Rentang tangan dari ujung- & $150 \mathrm{~cm}^{2}$ & $11.5 \mathrm{~cm}^{2}$ \\
4 & Ljung jari & $30 \mathrm{Kg}$ & $3 \mathrm{Kg}$ \\
5 & Bebar telapak kaki & $23 \mathrm{DoF}$ & $25 \mathrm{DoF}$ \\
\hline \hline
\end{tabular}

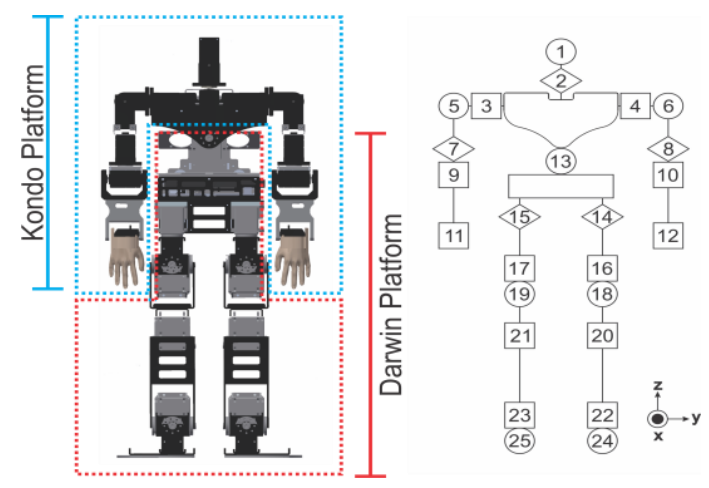

Gambar 9. Desain Mekanik Robot Humanoid.

Dari Tabel 2, robot humanoid ini bisa dikatakan sesuai dengan peraturan yang ada. Desain robot, diagram derajat kebebasan serta distribusi servo dapat dilihat pada gambar 9. 
Derajat kebebasan berjumlah 25 aktuator dengan distribusi nomor 1 sampai 12 menggunakan servo KRS2552HV dari platform Kondo sedangkan nomor 13 sampai 25 menggunakan servo Dynamixel MX-28T dari platform Robotis.

\section{B. Perancangan Sistem Elektronik}

Robot yang telah dirancang tidak bisa berjalan sesuai yang kita harapkan apabila tidak ada kecerdasan buatan yang ditanam pada robot. Oleh karena itu, robot memerlukan sistem elektronik yang dapat menjalan seluruh program. Diagram sistem elektronik dapat dilihat pada gambar 10. Seluruh komponen elektronik ini diletakkan pada badan robot. Pada Kontes Robot Seni Tari Indonesia, robot diharuskan dapat menari ketika ada lagu dan berhenti ketika lagu di mute. Untuk itu perlu sebuah rangkaian Sensor Suara untuk mendeteksi lagu yang dikirimkan oleh juri melalui Bluetooth audio transmitter ke Bluetooth audio receiver pada robot. Output dari Bluetooth audio receiver dimasukkan ke input sensor suara lalu melalui beberapa rangkaian elektronik. Output sensor suara ini berupa level suara (satuan dB) lalu dimasukkan ke pin ADC (Analog Digital Converter) Arduino Nano.

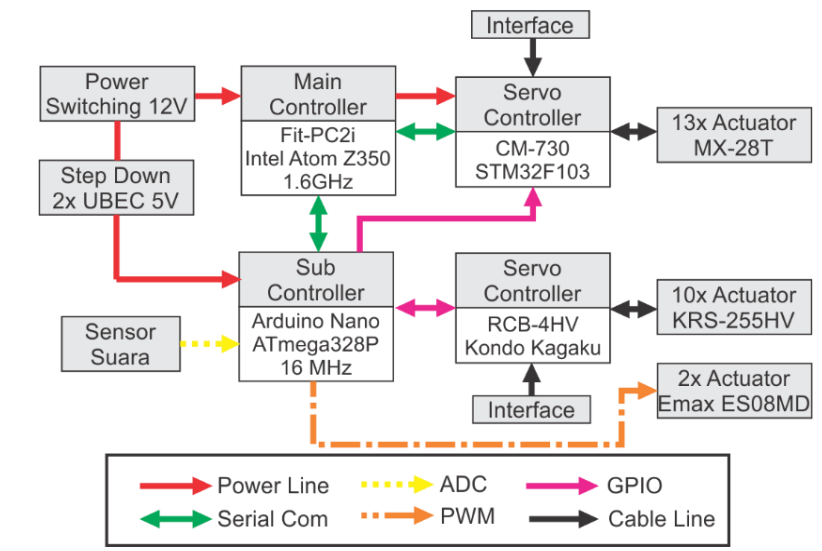

Gambar 10. Desain Sistem Elektronik Robot.

Penggunaan mini PC jenis FitPC2i pada robot humanoid ini berfungsi sebagai pemroses utama dengan sistem operasi berbasis linux. PC ini juga berfungsi untuk membuat motion dengan software Roboplus Motion yang selanjutnya akan diproses oleh subcontroller CM-730 yang berbasis ARM untuk mengontrol seluruh motor servo MX-28T sebanyak 13 buah. Main Controller ini menerima data serial dari Arduino Nano dan CM-730. Data serial tersebut selanjutnya akan diolah di Main Controller untuk dijadikan referensi untuk menjalankan Servo atau menghentikannya ketika tidak ada lagu.

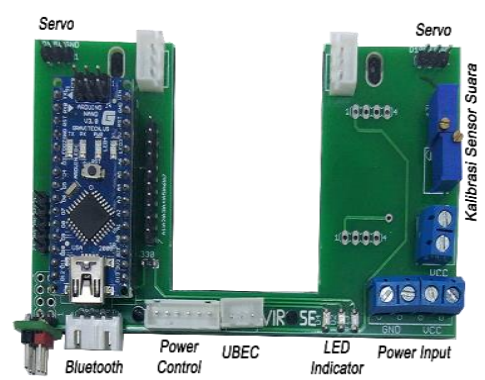

Gambar 11. Board Sub Controller Arduino Nano.

Sub Controller pada robot humanoid virose ini menggunakan dua board, yaitu Arduino Nano dan CM-730.
Sub controller ini mempunyai fungsi yang berbeda, Arduino Nano berfungsi sebagai pengolah data sensor suara sedangkan CM-730 berfungsi untuk mengontrol servo Dynamixel MX-28T pada masing-masing joint robot sehingga CM-730 ini bisa disebut servo controller juga. Selain untuk mengontrol servo MX-28T, CM-730 juga mengirimkan data tombol dari interface untuk dikirimkan ke main controller. Kedua sub controller ini terhubung ke main controller menggunakan jalur komunikasi serial dan dapat dimonitor melalui main controller apabila ada error saat proses pengiriman.

\section{Desain Komunikasi Antar Robot}

Pada Kontes Robot Seni Tari Indonesia, robot yang digunakan berjumlah dua unit. Maka dari itu, dirancanglah komunikasi antara dua robot agar dapat serasi dalam melakukan setiap gerakan. Dua robot tersebut kita sebut master dan slave. Pada perancangan elektronik robot slave tidak memiliki beberapa komponen elektronik seperti tidak adanya sensor suara, karena semua kendali pada robot master. Sistem komunikasi sendiri menggunakan Bluetooth HC-05 yang sudah dihubungkan pair. Skema komunikasi antar robot seperti pada Gambar 12.

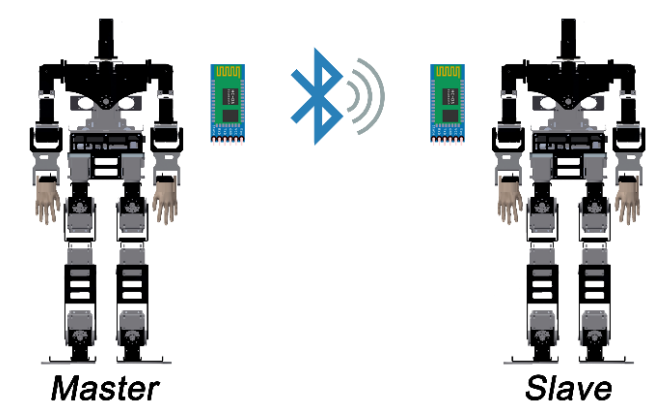

Gambar 12. Komunikasi Antar Robot.

\section{Implementasi Desain Mekanik Robot}

Setelah proses desain mekanik selesai, selanjutnya akan melalui proses fabrikasi part alumunium menggunakan beberapa mesin pendukung seperti mesin laser cutting, mesin bending dan mesin welding. Beberapa part dibuat menggunakan mesin 3D Print seperti pada bagian telapak tangan. Proses fabrikasi part ini dilakukan di perusahaan Dempo Metal Laserindo, Rungkut, Surabaya. Seluruh part hasil fabrikasi selanjutnya dirakit menjadi robot.

Dalam proses perakitan sendiri ada beberapa part yang harus dimodifikasi seperti penambahan ulir menggunakan handtap, bending dan proses welding. Servo Dynamixel MX-28T yang akan dipasangkan ke part alumunium harus dikalibrasi dan diatur titik tengahnya, begitu juga dengan servo KRS-2552HV ini. Desain robot humanoid ini bisa dilihat pada gambar 13 .

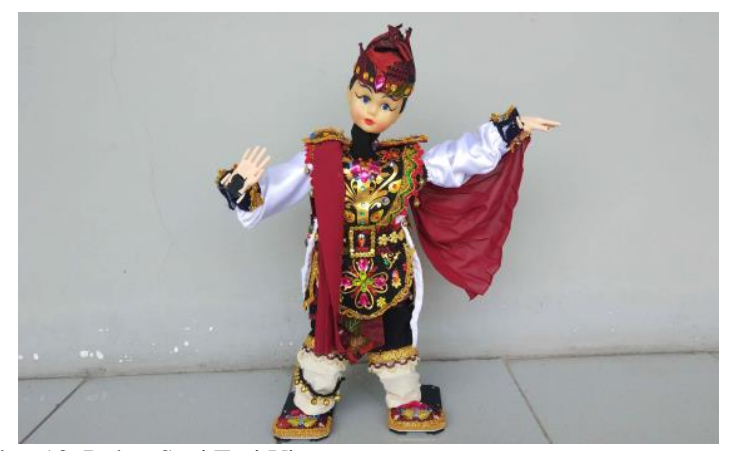

Gambar 13. Robot Seni Tari Virose. 


\section{PENGUJIAN DAN PEMBAHASAN}

Pengujian-pengujian yang dilakukan meliputi pengujian sensor suara, pengujian komunikasi antar robot dan pengujian tarian remo pada robot. Robot humanoid virose ini juga akan melakukan pengujian pada seleksi tingkat regional di Politeknik Negeri Malang pada tanggal 1 -3 Mei 2018 dan akan lanjut ke tingkat nasional yang akan diselenggarakan di Universitas Negeri Yogyakarta pada tanggal 11 - 14 Juli 2018.

\section{A. Pengujian Sensor Suara}

Pengujian sensor suara sebelum di implementasikan ke robot perlu dilakukan supaya didapatkan nilai threshold dan respon dari sensor suara tersebut. Diharapkan dengan adanya pengujian ini robot dapat merespon adanya suara yang ditransferkan oleh juri melalui Bluetooth audio. Berikut grafik dari respon sensor suara yang digunakan:

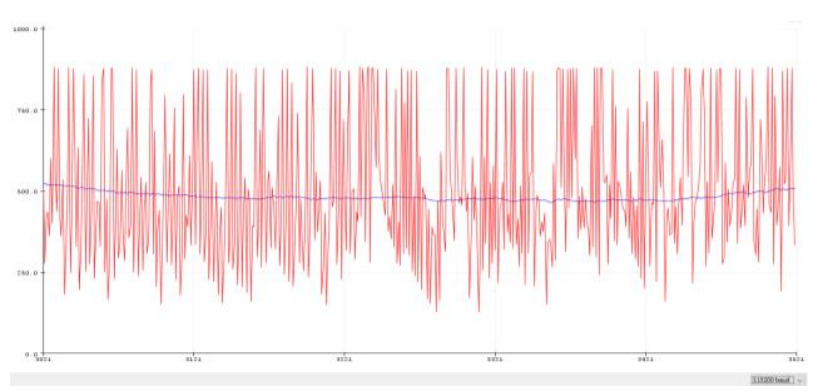

Gambar 15. Grafik Output Sensor Suara.

\section{B. Pengujian Komunikasi Main Controller dengan Sub Controller}

Pengujian ini bertujuan untuk melihat respon pada robot ketika pengiriman data dari sensor suara ke main controller. Robot akan berhenti ketika sub controller Arduino Nano mengirim data serial character 'A' dan CM-730 mengirim nilai $\mathrm{ADC}<200$. Apabila main controller menerima data serial ' $B$ ' atau CM-730 mengirim nilai $A D C \geq 200$ maka robot akan melakukan gerakan. Tabel 3 kebenaran yang diterapkan pada robot humanoid Virose.

Tabel 3.

Truth Table pada Robot

\begin{tabular}{ccc}
\multicolumn{3}{c}{ Truth Table pada Robot } \\
\hline \hline \multicolumn{2}{c}{ Input } & Output \\
\hline Serial Data & ADC & STOP \\
\hline 'A' & $<200$ & GO \\
'A' & $\geq 200$ & GO \\
'B' & $<200$ & GO \\
'B' & $\geq 200$ & . \\
\hline \hline
\end{tabular}

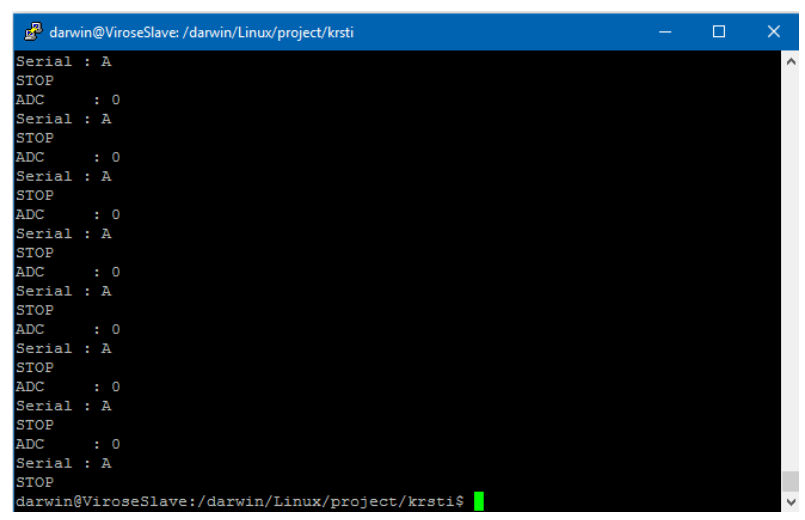

Gambar 16. Monitoring Robot dengan Kondisi STOP.
Pada pengujian ini robot berhasil melakukan simulasi sesuai dengan truth table. Hasil monitoring robot dapat dilihat pada gambar 16 saat keadaan 'STOP' dan gambar 17 saat keadaan 'GO'

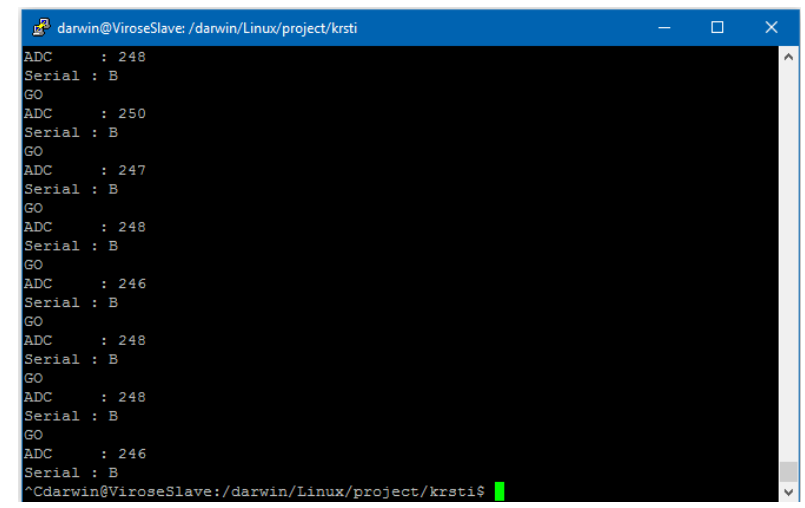

Gambar 17. Monitoring Robot dengan Kondisi GO.

\section{Pengujian Tarian Remo pada Robot}

Pada pengujian ini, robot akan melakukan beberapa varian gerakan seperti berjalan, Gejugan, Sabetan, tarian sembah pembuka, tari zona $\mathrm{A}$, tari zona $\mathrm{B}$, tari zona $\mathrm{C}$ dan sembah penutup.

1. Gerakan Dasar Kaki

Pada tari remo, gerakan dasar pada bagian kaki terdiri dari Jalan, Gejugan, dan Sabetan. Gerakan dasar jalan sama seperti manusia pada umumnya, kaki kiri dan kaki kanan secara bergantian melangkah. Gejugan adalah posisi kaki dalam kondisi kuda-kuda sedangkan kaki kiri atau kanan melakukan nggejug ke lantai beberapa kali. Sedangkan Sabetan adalah posisi dimana kaki sebelah kanan diangkat setinggi lutut lalu melakukan sabetan pada selendang.

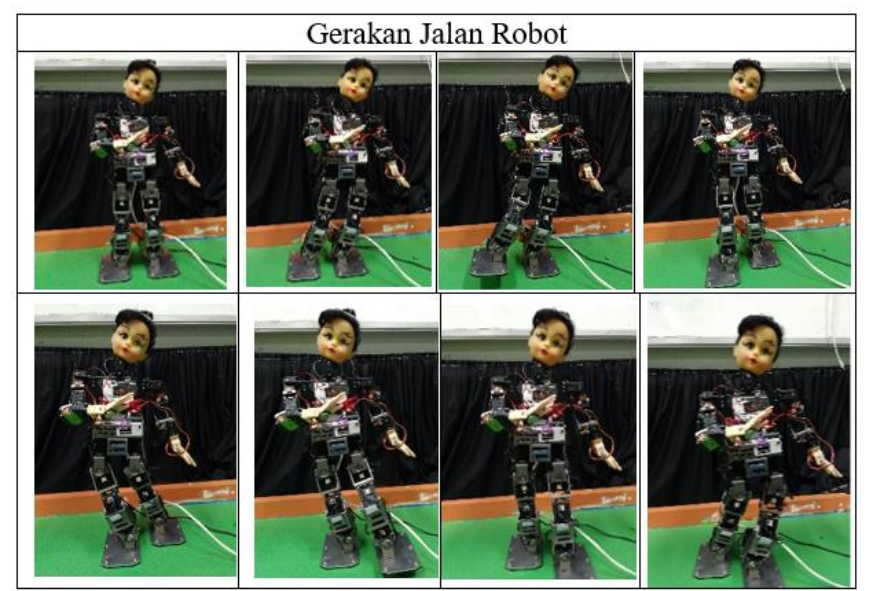

Gambar 18. Pola Berjalan Robot.

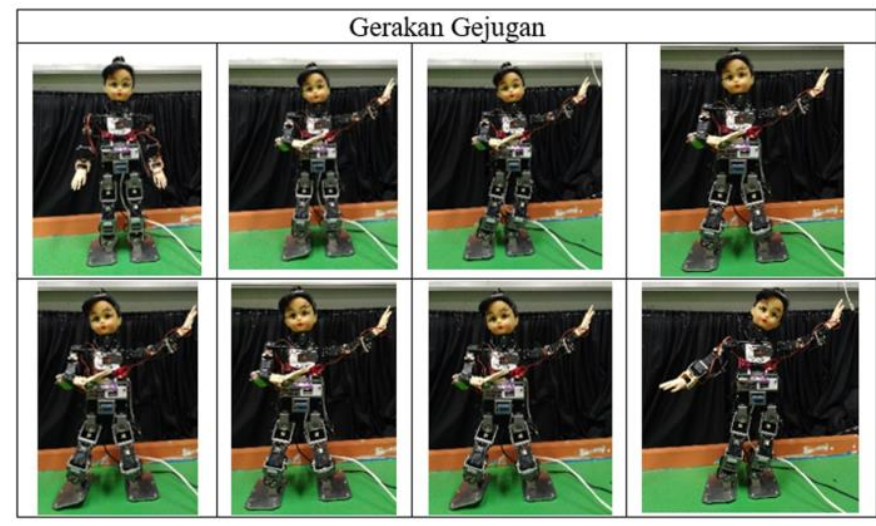

Gambar 19. Pola Gerakan Gejugan. 


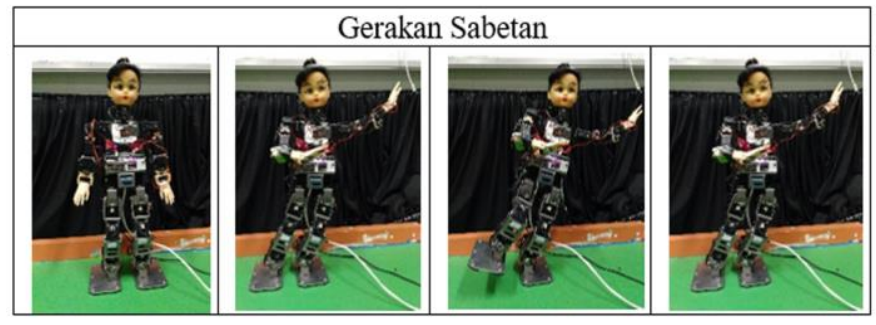

Gambar 20. Pola Gerakan Sabetan.

Tabel 4.

Hasil Penilaian 14 besar KRSTI tingkat Nasional

\begin{tabular}{|c|c|c|c|c|}
\hline Nama Tim & P1 & P2 & P3 & Nilai \\
\hline Rosemery (UNY) & 84.67 & 73.67 & 75.33 & 77.89 \\
\hline Azzahraly (UNESA) & 76.33 & 77.67 & 77.00 & 77.00 \\
\hline ERISA (PENS) & 77.00 & 77.00 & 76.00 & 76.67 \\
\hline VI-ROSE (ITS) & 75.00 & 75.67 & 73.00 & 74.56 \\
\hline Lanange Jagad (UAD) & 70.33 & 73.00 & 78.00 & 73.78 \\
\hline CMCS ART (PNUP) & 73.67 & 70.00 & 72.67 & 72.11 \\
\hline Dago Concordia (ITB) & 70.67 & 76.33 & 64.67 & 70.56 \\
\hline Nakula Nayaka (UB) & 71.00 & 69.67 & 71.00 & 70.56 \\
\hline Badaya SAS (TelU) & 66.00 & 66.67 & 70.00 & 67.56 \\
\hline EURO ARTE (USR) & 67.67 & 62.33 & 68.00 & 66.00 \\
\hline ALFAN (UGM) & 58.67 & 66.00 & 68.67 & 64.44 \\
\hline $\begin{array}{l}\text { Robogen (STMIK } \\
\text { Lampung) }\end{array}$ & 53.67 & 65.67 & 58.33 & 59.22 \\
\hline Jan'nah (UNNES) & 40.00 & 60.33 & 69.00 & 56.44 \\
\hline Pagaruyung (UNP) & 48.00 & 59.00 & 55.33 & 54.11 \\
\hline
\end{tabular}

2. Pengujian Robot di KRSTI tingkat Nasional

Pengujian ini bertujuan untuk mengetahui performa robot dari segi gerakan, stabilitas, dan komunikasi. Pengujian ini dilakukan di Universitas Muhammadiyah
Yogyakarta pada tanggal 11 - 14 Juli 2018. Tabel 4 merupakan tabel nilai yang diperoleh dari dewan juri.

\section{KESIMPULAN}

Berdasarkan percobaan yang telah dilakukan pada pelaksanaan tugas akhir ini didapat beberapa kesimpulan sebagai berikut:

1. Desain mekain robot humanoid virose ini berhasil diimplementasikan, robot dapat melakukan gerakan tari remo dengan rancak.

2. Desain elektronik dan komunikasi pada robot sudah dapat diimplementasikan pada robot. Dengan penambahan beberapa kemungkinan yang mungkin bisa saja terjadi.

3. Dari hasil pengujian di tingkat Nasional, robot ini mampu memperoleh hasil yang sangat memuaskan dengan menjadi juara 2

\section{DAFTAR PUSTAKA}

[1] Joseph Rudy, "Zero Moment Point Walking Controller for Humanoid Walking using Drwin-OP,” University of Notre Dame, Indiana, 2014.

[2] Direktorat Jenderal Pembelajaran dan Kemahasiswaan Kementrian Riset, Teknologi, dan Pendidikan Tinggi, "Kontes Robot Seni Tari Indonesia 2018," in Buku Panduan KRSTI 2018, Panitia Kontes Robot Seni Tari Indonesia 2018, p. 5 .

[3] I. Ha, Y. Tamura, and H. Asama, "Development of open platform humanoid robot DARwIn-OP,” vol. 27, pp. 223-232, Feb. 2013

[4] “http://support.robotis.com/en/product/darwin-op.htm," 12-Mei-2018.

[5] "https://kondo-robot.com/product/khr-3hv-ver-2-life," KHR-3HV Ver.2, 15-Jul-2018. 